\title{
Editorial
}

\section{Processing-Structure-Property Relationships in Metals}

\author{
Roberto Montanari * and Alessandra Varone * \\ Department of Industrial Engineering, University of Rome "Tor Vergata”, Via del Politecnico 1, 00133 Rome, Italy \\ * Correspondence: roberto.montanari@uniroma2.it (R.M.); alessandra.varone@uniroma2.it (A.V.)
}

Received: 12 August 2019; Accepted: 14 August 2019; Published: 19 August 2019

check for updates

\section{Introduction and Scope}

The increasing demand for advanced materials in construction, transportation, communications, medicine, energy production, as well as in several other fields, is the driving force for investigating the processing-structure-property relationships. In the industrial manufacturing of metals, the achievement of products featuring the desired characteristics always requires the control of process parameters in order to achieve a suitable microstructure. The close relationship among process parameters, microstructure, and mechanical properties is a matter of interest in such different areas as foundry, plastic forming, sintering, welding, etc., and is relevant for both well-established and innovative processes.

Nowadays, circular economy and sustainable technological development are dominant paradigms and impose an optimised use of resources, a lower energetic impact of industrial processes, and new tasks for materials and products. In this frame, this Special Issue of Metals covers a broad range of research works, and contains both research and review papers. There is particular focus on novel processes and recent advancements in testing methods and computational simulations that are able to characterise and describe microstructural features and mechanical properties.

\section{Contributions}

The book gathers manuscripts from academic and industrial researchers with stimulating new ideas and original results. It consists of one review paper regarding state of art and perspectives of alloys for aeronautic applications [1] and fifteen research papers [2-16] focused on different materials and processes.

A group of papers deals with the effect of ultra-fine or nanostructured grains on the mechanical properties, the materials are: a low-carbon steel processed by cryorolling [2], Mg-10Y-6Gd-1.5Zn-0.5Zr alloy submitted to two different heat treatments [3], AZ91 Mg alloy prepared by ECAP plus aging [4], hard nanostructured coatings deposited on a $\mathrm{S600}$ high speed steel [5], and pure $\mathrm{Cu}$ deformed by simple shear extrusion, namely two forward and two reversed simple shear straining stages on two different slip planes [6]. The different routes used to produce ultra-fine or nanostructured grains introduce a variety of microstructures in terms of: (i) dislocation density and arrangement; (ii) size and orientation distribution of the grains; and (iii) size, shape, and fraction of secondary phases. These works highlight different aspects of the same problem, namely the fundamental role played by microstructural homogeneity on mechanical characteristics.

The paper by Campari et al. [7] focuses on the change of mechanical behaviour taking place in thin metal films (self-sustained and deposited on a rigid substrate) as their thickness becomes comparable to grain size. The topic is of great scientific interest and practical relevance because thin films have increasing applications in packaging, microelectromechanical systems (MEMS), sensors, and electronic device technologies.

Another topic of utmost importance is the prediction of process-structure-property relationships for a given material that can be achieved either through suitable models or experiments. The work by 
Fiorese et al. [8] describes a tool used for predicting the effect of the plunger motion on the properties of high-pressure die cast aluminium alloys. In fact, the proposed model is a general methodology independent of the machine and accounts for the effects of geometry and alloy through its coefficients.

Computer-aided design (CAD) and finite element (FE) analysis were employed by Gloria et al. [9] in order to investigate the effect of the material-shape combination of metal posts on the mechanical behaviour of endodontically treated anterior teeth.

Predicting the final properties of the Ti-TiAl-B4C system is investigated through an experimental approach by Montealegre-Melendez et al. [10]. Ti-TiAl-B4C is an alternative material to high specific modulus alloys for the aerospace industry, but the mechanical properties are strongly affected by the secondary phases, which form in situ during fabrication and depend on the processing conditions and composition of the starting materials. The results demonstrate that the relations between microstructure and properties can be predicted in terms of the processing parameters of the titanium matrix composites fabricated by powder metallurgy. In particular, prealloyed TiAl provides the best precursor for the formation of the reinforcement phases from $1100^{\circ} \mathrm{C}$ regardless of the pressure.

An innovative post hot-forging process for 7050 aluminium alloys is proposed by Angella et al. [11]. Unlike AMS4333 and AMS2770N standards requiring cold working after solution heat treatment and prior to aging, the new method adopts an intermediate warm deformation step, which allows improving the fracture's toughness behaviour without significantly affecting tensile properties. Such result is achieved by reducing the material's heterogeneity with finer grain and subgrains pinned by precipitates.

Another relevant contribution to the Special Issue is provided by Lee and Jeong [12]. The authors study the effect of the calibre-rolling speed on the microstructure and microtexture of $\mathrm{Nb}$ tubes used as superconductivity materials. These investigators found that the dislocation density increases with rolling speed owing to the Peierls mechanism. Moreover, electron backscatter diffraction (EBSD) shows how a higher calibre-rolling speed weakens the $<111>$ fibre texture in favour of the $<112>$ one involving a higher fraction of coincident site lattice (CSL) boundaries $\Sigma 3$ with low energy.

The feasibility of a novel casting process, tailored additive casting (TAC), has been demonstrated in [13]. In this process, the melt is injected several times to fabricate a single component, with a few seconds of holding between successive injections. Using TAC commercial steering knuckles, important components of automotive suspension systems have been successfully produced through an Al 6061 alloy of optimized composition.

Zhu et al. [14] report about a 1500-MPa-grade bainite rail developed and produced in an industrial production line. Nowadays, pearlite rail is widely used in the construction of railways, although high-speed and heavy-loading railways require steels with higher strength, toughness, and wear resistance. Bainite rails guarantee better mechanical properties than pearlite rails.

Finally, the papers by Tocci et al. [15] and Maizza et al. [16] deal with additive manufacturing (AM), an innovative technology for the production of parts and prototypes based on layer-by-layer build-up that allows an unrivaled design freedom, not reachable via conventional manufacturing routes combined with high quality and outstanding mechanical properties. The examined samples were produced by means of different techniques: direct metal laser sintering (DMLS) of Scalmalloy powder [15] and selective electron beam melting (SEBM) of Ti-6Al-4V alloy [16]. Both papers highlight the specific microstrucural features of the materials related to the parameters of the production process and the consequences on mechanical performances. Moreover, Maizza et al. [16] give quite an original contribution to the benchmark of AM products by applying the macroinstrumented indentation test for the nondestructive determination of local tensile-like properties.

Acknowledgments: As Guest Editors, we would like to especially thank Kinsee Guo, Assistant Editor for his support and active role in the publication. We are also grateful to the entire staff of Metals Editorial Office for the precious collaboration. Furthermore, we are thankful to all of the contributing authors and reviewers; without your excellent work it would not have been possible to accomplish this Special Issue that we hope will be a piece of interesting reading and reference literature.

Conflicts of Interest: The authors declare no conflict of interest. 


\section{References}

1. Gloria, A.; Montanari, R.; Richetta, M.; Varone, A. Alloys for Aeronautic Applications: State of the Art and Perspectives. Metals 2019, 9, 662. [CrossRef]

2. Yuan, Q.; Xu, G.; Liu, S.; Liu, M.; Hu, H.; Li, G. Effect of Rolling Reduction on Microstructure and Property of Ultrafine Grained Low-Carbon Steel Processed by Cryorolling Martensite. Metals 2018, 8, 518. [CrossRef]

3. Liu, H.; Huang, H.; Wang, C.; Ju, J.; Sun, J.; Wu, Y.; Jiang, J.; Ma, A. Comparative Study of Two Aging Treatments on Microstructure and Mechanical Properties of an Ultra-Fine Grained Mg-10Y-6Gd-1.5Zn-0.5Zr Alloy. Metals 2018, 8, 658. [CrossRef]

4. Yang, Z.; Ma, A.; Liu, H.; Sun, J.; Song, D.; Wang, C.; Yuan, Y.; Jiang, J. Multimodal Microstructure and Mechanical Properties of AZ91 Mg Alloy Prepared by Equal Channel Angular Pressing plus Aging. Metals 2018, 8, 763. [CrossRef]

5. Santecchia, E.; Cabibbo, M.; Magid, A.; Hamouda, S.; Musharavati, F.; Popelka, A.; Spigarelli, S. Investigation of the Temperature-Related Wear Performance of Hard Nanostructured Coatings Deposited on a S600 High Speed Steel. Metals 2019, 9, 332. [CrossRef]

6. Bagherpour, E.; Qods, F.; Ebrahimi, R.; Miyamoto, H. Microstructure and Texture Inhomogeneity after Large Non-Monotonic Simple Shear Strains: Achievements of Tensile Properties. Metals 2018, 8, 583. [CrossRef]

7. Campari, E.G.; Amadori, S.; Bonetti, E.; Berti, R.; Montanari, R. Anelastic Behavior of Small Dimensioned Aluminum. Metals 2019, 9, 549. [CrossRef]

8. Fiorese, E.; Bonollo, F.; Battaglia, E. A Tool for Predicting the Effect of the Plunger Motion Profile on the Static Properties of Aluminium High Pressure Die Cast Components. Metals 2018, 8, 798. [CrossRef]

9. Gloria, A.; Maietta, S.; Richetta, M.; Ausiello, P.; Martorelli, M. Metal Posts and the Effect of Material-Shape Combination on the Mechanical Behavior of Endodontically Treated Anterior Teeth. Metals 2019, 9, 125. [CrossRef]

10. Montealegre-Meléndez, I.; Arévalo, C.; Pérez-Soriano, E.M.; Kitzmantel, M.; Neubauer, E. Microstructural and XRD Analysis and Study of the Properties of the System Ti-TiAl-B4C Processed under Different Operational Conditions. Metals 2018, 8, 367. [CrossRef]

11. Angella, G.; Di Schino, A.; Donnini, R.; Richetta, M.; Testani, C.; Varone, A. AA7050 Al Alloy Hot-Forging Process for Improved Fracture Toughness Properties. Metals 2019, 9, 64. [CrossRef]

12. Lee, J.; Jeong, H. Effect of Rolling Speed on Microstructural and Microtextural Evolution of $\mathrm{Nb}$ Tubes during Caliber-Rolling Process. Metals 2019, 9, 500. [CrossRef]

13. Jeon, G.T.; Kim, K.Y.; Moon, J.H.; Lee, C.; Kim, W.J.; Kim, S.J. Effect of Al 6061 Alloy Compositions on Mechanical Properties of the Automotive Steering Knuckle Made by Novel Casting Process. Metals 2018, 8, 857. [CrossRef]

14. Zhu, M.; Xu, G.; Zhou, M.; Yuan, Q.; Tian, J.; Hu, H. Effects of Tempering on the Microstructure and Properties of a High-Strength Bainite Rail Steel with Good Toughness. Metals 2018, 8, 484. [CrossRef]

15. Tocci, M.; Pola, A.; Girelli, L.; Lollio, F.; Montesano, L.; Gelfi, M. Wear and Cavitation Erosion Resistance of an AlMgSc Alloy Produced by DMLS. Metals 2019, 9, 308. [CrossRef]

16. Maizza, G.; Caporale, A.; Polley, C.; Seitz, H. Micro-Macro Relationship between Microstructure, Porosity, Mechanical Properties, and Build Mode Parameters of a Selective-Electron-Beam-Melted Ti-6Al-4V Alloy. Metals 2019, 9, 786. [CrossRef]

(C) 2019 by the authors. Licensee MDPI, Basel, Switzerland. This article is an open access article distributed under the terms and conditions of the Creative Commons Attribution (CC BY) license (http://creativecommons.org/licenses/by/4.0/). 